\title{
Quantitative determination of modal content and morphological properties of coal sulphides by digital image analysis as a tool to check their flotation behaviour ${ }^{\text {th }}$
}

\author{
E. Coz ${ }^{\mathrm{a}}$, R. Castroviejo ${ }^{\mathrm{a}}$, D. Bonilla ${ }^{\mathrm{b}}$, F.J. García Frutos ${ }^{\mathrm{c}, *}$ \\ ${ }^{\text {a }}$ ETS Ingenieros de Minas, c/Rios Rosas 21, 28003 Madrid, Spain \\ ${ }^{\mathrm{b}}$ S.A. Hullera Vasco-Leonesa, Carretera de Alcedo s/n, La Robla, 24640 Leon, Spain \\ ${ }^{\mathrm{c}}$ Centro de Investigaciones Engergeticas Medioambientales y Tecnologicas (CIEMAT), Fossil Fuels Department, \\ Avda.Complutense 22 Edificio 20, 28040 Madrid, Spain
}

\begin{abstract}
An efficient depression of coal sulphides in the flotation process means a healthier environment and may be essential for the sustainability of a coal operation. Nitric and ferric oxidative pre-treatment of coal pyrite have been tested to improve pyrite depression, and the results are compared with those from the process of raw, not pre-treated coal. The removal indexes point to nitric pre-treatment as the best, but depression is still low. The microscopic study of feed and products, coupled to Digital Image Analysis (DIA) in all the cases, provide important clues to understand the behaviour of pyrite, which can be related to quantitative parameters, such as the exposition ratio (ER), and to qualified interpretation of the textures. Pyrite shows in the first float an unexpected hydrophobic behaviour, which is due to its occurrence as framboids, or porous particles which may be intergrown with organic matter and behave as coal. In general, the flotation results can be predicted from the DIA-data, e.g. depression of liberated pyrite into the tailings, increased by oxidative pre-treatments by $300 \%$ (ferric) or by $>400 \%$ (nitric); or concentration of middlings with lower pyrite ER in the floats. DIA is an efficient tool to obtain some important quantitative informations which otherwise would be inaccessible (e.g. the morphological data on $>1,000,000$ pyrite particles for this study), and its use should be enhanced to check ore processing.
\end{abstract}

\section{Introduction}

Pyrite depression is of great importance in coal flotation, since pyrite is a common gangue mineral. In many coal flotation operations, a significant amount of pyrite present in coal floats jointly with carbonaceous matter, rising the sulphur content of the clean product and reducing its economic value. The pyrite depression is more difficult in coal-pyrites because they have more hidrophobicity than mineral pyrites. Understanding the behaviour of pyrite in coal requires a detailed mineralogical study of the sulphide phase, distinguishing the various forms in which it is present. This has been carried out by means of reflected light microscopy on a selection of polished coal samples; the observations were then quantified with a digital image analyser (DIA) coupled to the microscope, through a three $\mathrm{CCD}$ video camera and a frame grabber.

A wide variety of pyrite-depressing agents have been studied and tested [1]. However, even if effective in laboratory experiments, they have not been adopted on a plant scale, apparently due to the variations in the natural hydrophobicity of pyrite. The floatability of pyrite depends on $\mathrm{pH}$ and surface properties, requiring a good control in the flotation parameters, usually beyond the capabilities of the existing coal flotation circuits [2]. In contrast to mineral pyrite, coal pyrite exhibits an abnormal flotation behaviour over a wide $\mathrm{pH}$ range. A modification in surface properties of pyrite oxidising it, could change its hydrophobicity and depress it. The changes in hydrophobicity are likely due to the formation of oxidised species (iron sulphates, iron 
hydroxides, etc.) on the pyrite surface when the oxidation conditions are favourable. These compounds are known to be flotation depressants.

To test this, the possibilities of depression of pyritic sulphur in a coal sample were studied using two oxidising agents: diluted solutions of ferric sulphate and nitric acid [2,3]. Many of the studies of coal pyrite depression using isolated samples of coal pyrite are not directly applicable to actual coal flotation systems. This work was conducted, however, on real coal samples, to research by DIA the form in which pyrite is recovered/depressed.

\section{Experimental}

\subsection{Materials}

Coal was first studied by reflected light microscopy to define its mineralogy (polished sections from hand samples of ROM coal, as well as from the milled products), and then processed. The mineralogy of the products from the process was studied as well, to obtain critical qualitative and quantitative information.

\subsection{Qualitative mineralogical study}

Microscopic (qualitative) characterization of the ores with reflected light microscopy shows that sulphides are generally scarce $(<2$ vol\%), and composed mostly of fine grained pyrite of two types (Figs. 1 and 2): (i) disseminated pyrite, occurring in small, micron-sized particles or aggregates, intergrown with coal in various ways; (ii) micro-banded pyrite, occurring in very thin layers or bands or in micro-veinlets, usually up to $\mathrm{mm}$ scale in length.

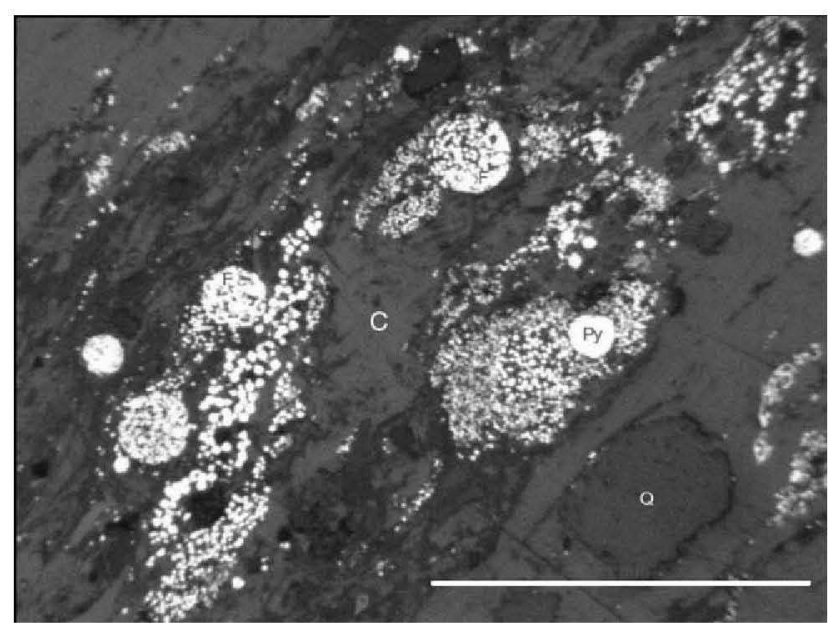

Fig. 1. Disseminated pyrite (Py, F) in coal (C), with minor carbonate and silicates (clays and quartz, Q); the pyrite is present mainly as framboids (labelled $\mathbf{F}$ ), although some minute crystalline pyrite grains can also be seen (e.g. the one labelled $\mathbf{P y}$, possibly a recrystallized framboid). Reflected light photomicrograph (sample CIE-HVL/06A); length of white bar (for scale) $=100 \mu \mathrm{m}$.

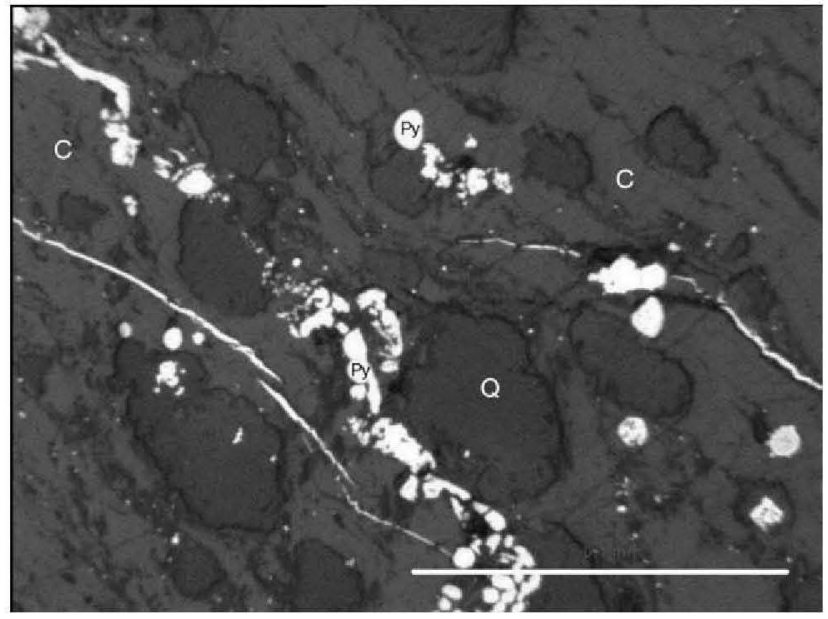

Fig. 2. Coal (C) with pyrite (Py) veinlets and bands, and also with some disseminated pyrite crystals and framboids (Py). Reflected light photomicrograph (sample CIE-HVL/06a); length of white bar (for scale) $=100 \mu \mathrm{m}$.

Trace amounts of other sulphides (marcasite, chalcopyrite), negligible for the purpose of this work, may occur as minute grains; as gangue minerals, usually disseminated silicates (clays, quartz) and carbonates are found. Recrystallization is not uncommon, and is sometimes associated with small-scale remobilization; these processes tend do enhance the presence of coarser grained and more crystalline, euhedral pyrite, or of the banded type. Among the disseminated type, the pyrite framboids or framboidal aggregates (formerly known as pyrite bacteria, [4]) are rather common: subspherical aggregates, usually some $5-50 \mu \mathrm{m}$ in diameter, composed of tiny pyrite particles (down to sub- $\mu \mathrm{m}$ size), which may be finely intergrown with coal. Quantitative determinations (modal or vol\% compositions, and grain-sizes) are presented with DIA results (Table 5).

\subsubsection{Processed materials}

A sample of the coal that is processed by flotation in the HVL plant was used. This sample (milled to $<0.5 \mathrm{~mm}$ ) was classified according to grain size by screening, and the $-53 \mu \mathrm{m}$ fraction was used as coal sample for this research. This particle size was selected to enhance the liberation of pyrite, which is usually fine grained.

The coal sample was analysed by ASTM standards methods to proximate, calorific value and sulphur forms (Table 1).

Table 1

Analysis of initial coal sample (db)

\begin{tabular}{llllll}
\hline $\begin{array}{l}\text { Particle } \\
\text { size }(\mu \mathrm{m})\end{array}$ & $\begin{array}{l}\text { Ash } \\
(\%)\end{array}$ & $\begin{array}{l}\text { Total } \\
\text { sulphur } \\
(\%)\end{array}$ & $\begin{array}{l}\text { Pyritic } \\
\text { sulphur } \\
(\%)\end{array}$ & $\begin{array}{l}\text { Organic } \\
\text { sulphur } \\
(\%)\end{array}$ & $\begin{array}{l}\text { G.C.V. } \\
(\mathrm{GJ} / \mathrm{t})\end{array}$ \\
\hline$<53$ & 33.6 & 2.2 & 1.5 & 0.7 & 22.58 \\
\hline
\end{tabular}




\subsection{Oxidative pre-treatment procedures}

Two reagents were used to oxidise the surface of pyrite present in coal trying to reduce its hydrophobicity: nitric acid and ferric sulphate. The tests were carried out in Erlenmeyer flasks with an orbital shaker at room temperature, using aqueous solutions of nitric acid and ferric sulphate (1-5\%, $\mathrm{w} / \mathrm{v}$ for nitric leaching, and $0.25-2 \mathrm{~g} / \mathrm{l}$ for ferric leaching), at $20 \%(\mathrm{w} / \mathrm{v})$ pulp density during different reaction times until $90 \mathrm{~min}$. Then, the pulps were filtered and the solid was washed with water until a neutral $\mathrm{pH}$ in the filtrate was obtained. Then the sample was dried.

\subsection{Flotation apparatus and procedure}

The pre-treated coal samples were submitted to flotation at the optima conditions. These were previously established using a glass micro-flotation column of $130 \mathrm{ml}$ provided with an air diffuser at the bottom. Two products were obtained: concentrate and tailing.

The flotation tests were carried out in a Denver laboratory flotation machine $(21$ cell). The results obtained with pre-treated samples in optima conditions were compared with those obtained with a coal sample without any pre-treatment (control flotation). The flotation tests were done at natural $\mathrm{pH}$ using a mixture of kerosene and the frother Nontoxol ${ }^{\odot}$ as flotation reagent. The pulp was conditioned for $2 \mathrm{~min}$ and floated for $5 \mathrm{~min}$. Four floated products (at 1,2,3 and $5 \mathrm{~min}$ ) and tailings were obtained. Concentrate, as a general term, means the sum of all the floated products, while the floated products obtained at 1 , $2, \ldots$ minutes are referred to as first, second float, etc. These products were analysed by ash, calorific value and total and pyritic sulphur.

\subsection{Digital image analysis}

The DIA analysis study was carried out separately on each relevant type of sample (feed and products), including ROM coal and differently processed samples (with or without pre-treatments); first and second floats were measured separately, as well as the tailings. The images were obtained through optical microscopic observation from polished sections of these materials.

\subsubsection{Characterization procedure and equipment}

After the qualitative mineralogical study, a quantitative study was undertaken by DIA, using (i) a Donphisa (Sony), 3 CCD colour video camera connected to (ii) a Leica Laborlux reflected light microscope to acquire the images of the samples, (iii) a Matrox-Meteor frame grabber to digitalise them, and (iv) the Aphelion image analysis software. The information processed relates to relative abundance (vol\% or modal contents of pyrite and coal) and to morphological/geometric parameters.

\subsubsection{Methodology}

Before the analysis, a control of the equipment response is required to guarantee the reliability of results [5]. Time and space drift, power fluctuations (feed stability), brightness and colour balance with respect to reference standards are kept under control, and noise is low (always below a few units \% of grey level), thus ensuring a reliable segmentation of pyrite, gangue and coal (cf. Reflectance values: [4,6]). The geometrical calibration gives a result of $0.31 \mu \mathrm{m}$ for each pixel in the image, using a $20 \times$ objective in the microscope.

The image acquisition was carried out along a systematic grid covering the whole surface of the section to ensure that the measures are representative of the results with respect to each sample. At deposit scale, the results must be taken with caution as for the pyrite content, because the relative statistical uncertainly of grade estimation increases for scarce minerals $[7,8]$, but the morphological data may still be very useful, at least as qualitative information.

Mathematic algorithms have been studied and programmed in order to differentiate pyrite, coal and gangue and finally obtain the best segmentation for the morphological analysis. A total number of 10 samples has been studied (Table 5); overall, nearly 20,000 images have been acquired and stored, and over one million particles have been detected and measured

\subsubsection{Parameters}

According to the objectives defined, the following parameters were measured:

- Modal (or vol\%) contents of coal and pyrite.

- Area and perimeter for each particle in coal, pyrite and mixed grains.

- Pyrite liberation ratio, that relates the amount of liberated pyrite to the total pyrite contained in the sample.

- Pyrite Exposition Ratio, which is measured as a fraction (\%) of the external perimeter for each mixed grain, and defined as the relative length of the external contour occupied by pyrite related to the contour length of the whole grain. It provides an estimate of the modal\% of pyrite in mixed grains which is exposed to reagents, because it is not locked inside the grain.

- Pyrite Morphological properties: elongation, circularity and roughness, measured in each pyrite grain.

- Pyrite Grain Size, defined as the equivalent diameter of the particle or the diameter of a circle of the same area.

\section{Results and discussion}

\subsection{Oxidative pre-treatment and micro-flotation}

\subsubsection{Nitric pre-treatment}

In the first tests, concentration of nitric acid and time of attack were optimised, obtaining the best results for 


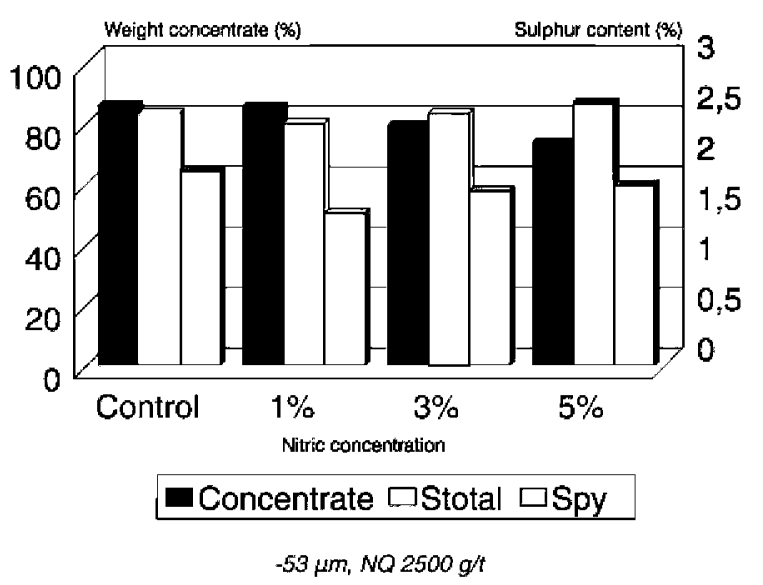

Fig. 3. Optimisation of nitric concentration.

a concentration of $1 \%$ during $60 \mathrm{~min}$ (Fig. 3). This figure shows the variation of weight and the total and pyritic sulphur content in concentrate for these tests. The dose of collector (or flotation reagent) was optimised using the removal indexes RTS and RIS [9], calculated as follows:

$$
\begin{aligned}
& \mathrm{RTS}=\frac{C\left(S_{\mathrm{F}}-S_{\mathrm{C}}\right)}{S_{\mathrm{F}}} \\
& \mathrm{RIS}=\frac{C\left(S_{\mathrm{PyF}}-S_{\mathrm{PyC}}\right)}{S_{\mathrm{PyF}}}
\end{aligned}
$$

being:

$C=$ Weight $(\%)$ of concentrate product

$S_{\mathrm{F}}=$ Total sulphur content $(\%)$ in feed

$S_{\mathrm{C}}=$ Total sulphur content $(\%)$ in concentrate product

$S_{\mathrm{PyF}}=$ Pyritic sulphur content $(\%)$ in feed

$S_{\mathrm{PyC}}=$ Pyritic sulphur content $(\%)$ in concentrate product

These indexes show the efficiency of the process for $S$ elimination. If there is no sulphur elimination in the floated

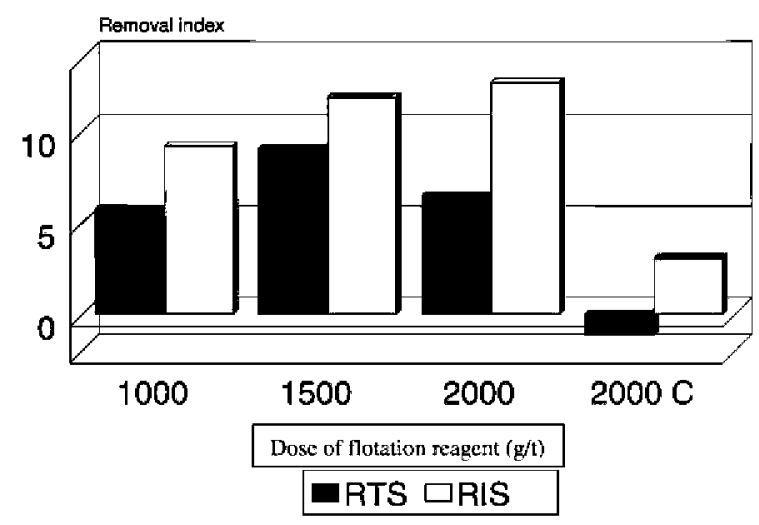

$-53 \mu \mathrm{m}$, Nitric $1 \%, 60$

Fig. 4. Optimisation of nitric pre-treatment ( $2000 \mathrm{C}$ is comparative to 2000 without pre-treatment).

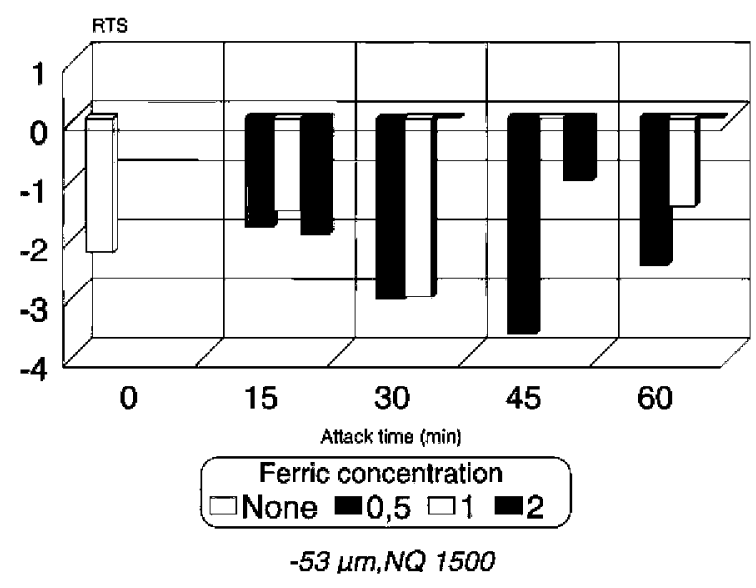

Fig. 5. Removal of total sulphur for ferric pre-treatment.

product with respect to the feed, RTS $=0$. If sulphur is concentrated in the floated product, RTS has negative values; finally, if sulphur is eliminated in tailings, RTS is positive. Fig. 4 represents the variation of removal indexes for total and pyritic sulphur. As can be observed, the best results (or higher removal indexes) were obtained with a collector dose of $1500 \mathrm{~g} / \mathrm{t}$.

\subsubsection{Ferric pre-treatment}

Figs. 5 and 6 show the removal indexes (RTS and RIS), comparatively, for the tests carried out with the ferric pre-treatment. Most of the RTS values are negative, and the best results are obtained with $2 \mathrm{~g} / \mathrm{l}$ during $30 \mathrm{~min}$ with a RTS $=0$ and a RIS $=3.91$.

\subsection{Oxidative pre-treatment and conventional flotation}

The coal samples pre-treated in optima conditions, as described earlier, were submitted to conventional flotation. Table 2 summarizes the results obtained for three tests: control flotation, ferric pre-treatment ( $2 \mathrm{~g} / \mathrm{l}, 30 \mathrm{~min})$ and nitric pre-treatment $(1 \%, 60 \mathrm{~min})$, for comparison. It shows that the elimination of pyritic sulphur is nearly $15 \%$ after oxidative pre-treatments,

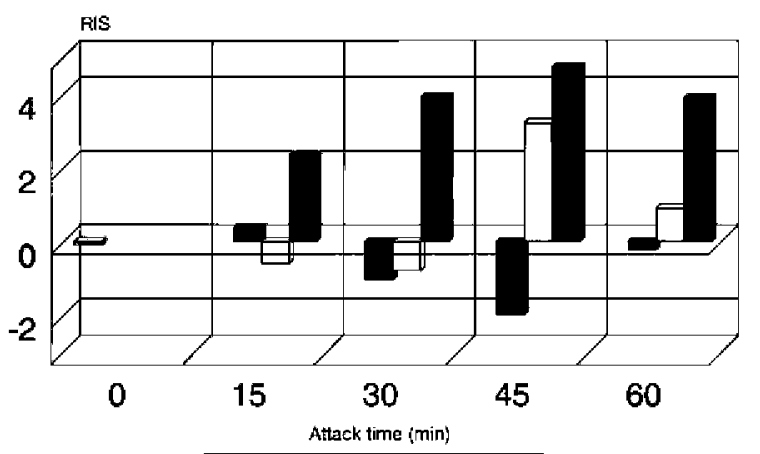

Ferric concentration $\square$ None $\square 0,5 \square 1 \square 2$

$-53 \mu \mathrm{m}, \mathrm{NQ} 1500$

Fig. 6. Removal of pyritic sulphur for ferric pre-treatment. 
Table 2

Conventional flotation results

\begin{tabular}{|c|c|c|c|c|c|c|c|c|}
\hline \multirow[t]{2}{*}{ Pre-treatment } & \multirow[t]{2}{*}{ Product } & \multirow[t]{2}{*}{ Weight $(\%)$} & \multicolumn{3}{|l|}{ Content $(\%)$} & \multicolumn{3}{|c|}{ Distribution $(\%)$} \\
\hline & & & Total sulphur & Pyritic sulphur & Ash & Total sulphur & Pyritic sulphur & Ash \\
\hline \multirow[t]{3}{*}{ None } & Concentrate & 83.02 & 2.28 & 1.71 & 23.99 & 92.76 & 93.60 & 61.14 \\
\hline & Tailing & 16.98 & 0.87 & 0.57 & 74.55 & 7.24 & 6.40 & 38.66 \\
\hline & Feed & 100.00 & 2.04 & 1.52 & 32.57 & 100.00 & 100.00 & 100.00 \\
\hline \multirow[t]{3}{*}{ Ferric } & Concentrate & 80.68 & 2.35 & 1.71 & 22.74 & 88.29 & 85.49 & 56.40 \\
\hline & Tailing & 19.32 & 1.30 & 1.21 & 73.41 & 11.71 & 14.51 & 43.60 \\
\hline & Feed & 100.00 & 2.15 & 1.61 & 32.53 & 100.00 & 100.00 & 100.00 \\
\hline \multirow[t]{3}{*}{ Nitric } & Concentrate & 82.65 & 2.34 & 1.58 & 22.26 & 89.58 & 85.29 & 58.16 \\
\hline & Tailing & 17.35 & 1.30 & 1.30 & 76.30 & 10.42 & 14.71 & 41.84 \\
\hline & Feed & 100.00 & 2.16 & 1.53 & 31.64 & 100.00 & 100.00 & 100.00 \\
\hline
\end{tabular}

Table 3

RTS and RIS values for conventional flotation tests

\begin{tabular}{lccc}
\hline Value & Control & Ferric & Nitric \\
\hline RTS & -9.74 & -7.62 & -6.91 \\
RIS & -10.60 & -4.83 & -2.62 \\
\hline
\end{tabular}

being about $6 \%$ without pre-treatment. However, if the removal indexes are compared (Table 3), although the values obtained for the tests with pre-treatment are higher than control flotation, all values are negative. This fact means that no depression of pyritic sulphur really exists. However, the sulphur contents present in tailings products after oxidative pre-treatments are higher than those with no pre-treatment, and in the former most of the sulphur is pyritic sulphur.

To understand the causes of these puzzling results, floats and tailings were studied by DIA to investigate the behaviour of pyrite in each product. The samples selected for this study include the floated products of the first and second minutes (separately) and the tailings products. The two floats selected (first and second floats) contain around $80 \%$ of the pyritic sulphur. The analysis of these products is shown summarily in Table 4.

\subsection{Digital image analysis}

A quantitative DIA of all the samples, seen through reflected light microscope, has been carried out. Its results, summarized in Table 5, show that the total amount of pyrite is small $(<2 \%$ modal, except in the tailings, where pyrite is concentrated), and that most of it is in mixed grains $(>85 \%$ of total pyrite), while most of the coal is liberated $(>95 \%)$. The pyrite content of mixed grains in the floats varies largely but in a systematic way, being tightly controlled by flotation time: total variation is between about 5 and $20 \%$ (modal), but variation in first floats is less than about 5\% (15.98-20.14\%), while in the second floats it is only $1.1 \%(4.98-5.99 \%)$. This pyrite is mostly blocked inside coal grains, i.e. not exposed to reagents, since the exposition ratio (or relative proportion of the external perimeter of mixed grains in which pyrite shows up) is low. This explains the poor results for the floats, since pyrite particles inside coal are not reached by any reagent, and the whole mixed particle will behave as coal; on the other hand, the exposition ratio is noticeably

Table 4

Characterisation of the flotation products selected for image analysis

\begin{tabular}{|c|c|c|c|c|c|c|c|}
\hline Pre-treatment & Product/reference & Weight (\%) & Total sulphur $(\%)$ & Pyritic sulphur $(\%)$ & Organic sulphur $(\%)$ & G.C.V. $(\mathrm{cal} / \mathrm{g})$ & $\operatorname{Ash}(\%)$ \\
\hline Feed & Feed EF-138 & 100.00 & 2.2 & 1.5 & 0.7 & 5393 & 33.6 \\
\hline \multirow[t]{3}{*}{ None } & First float EF-366 & 47.29 & 2.2 & 1.58 & 0.62 & 7049 & 1527 \\
\hline & Second float EF-367 & 23.03 & 2.5 & 2 & 0.5 & 5979 & 27.54 \\
\hline & Tailing EF-370 & 16.98 & 0.87 & 0.57 & 0.30 & 1157 & 74.55 \\
\hline \multirow[t]{3}{*}{ Ferric } & First float EF-371 & 54.13 & 2.2 & 1.50 & 0.70 & 7059 & 1538 \\
\hline & Second float EF-372 & 17.56 & 2.8 & 2.36 & 0.4 & 5598 & 31.50 \\
\hline & Tailing EF-375 & 19.32 & 1.3 & 1.21 & 0.09 & 1324 & 73.41 \\
\hline \multirow[t]{3}{*}{ Nitric } & First float EF-376 & 58.73 & 2.2 & 1.47 & 0.73 & 7192 & 15.26 \\
\hline & Second float EF-377 & 15.66 & 2.8 & 2.4 & 0.4 & 5371 & 32.77 \\
\hline & Tailing EF-380 & 17.35 & 1.30 & 1.30 & - & 1003 & 76.30 \\
\hline
\end{tabular}


Table 5

Pyrite content and characterization by DIA of each product

\begin{tabular}{|c|c|c|c|c|c|c|c|c|c|}
\hline \multirow[t]{2}{*}{ Pre-treatment } & \multirow[t]{2}{*}{ Product } & \multirow[t]{2}{*}{ Sample } & \multirow{2}{*}{$\begin{array}{l}\text { Py modal } \\
\text { content }(\%)\end{array}$} & \multicolumn{2}{|c|}{ Py distribution } & \multirow{2}{*}{$\begin{array}{l}\text { Modal Py content } \\
\text { of mixed grains } \\
(\%)\end{array}$} & \multirow{2}{*}{$\begin{array}{l}\text { Py exposition } \\
\text { ratio }(\%)\end{array}$} & \multicolumn{2}{|l|}{ Py grain size } \\
\hline & & & & $\begin{array}{l}\text { Liberated } \\
(\%)\end{array}$ & $\begin{array}{l}\text { Mixed } \\
(\%)\end{array}$ & & & $\begin{array}{l}\text { Total Py } \\
\text { (mean } \mu \mathrm{m})\end{array}$ & $\begin{array}{l}\text { Liberated Py } \\
\text { (mean } \mu \mathrm{m} \text { ) }\end{array}$ \\
\hline \multirow[t]{2}{*}{$\begin{array}{l}\text { ROM COAL } \\
\text { (not processed) }\end{array}$} & $\begin{array}{l}\text { ROM COAL } \\
\text { (hand sample) }\end{array}$ & CIE-HVL/06 & 1.10 & 0.00 & 100.00 & - & 0.00 & - & - \\
\hline & & CIE-HVL/06A & 1.49 & 0.00 & 100.00 & - & 0.00 & - & - \\
\hline Mill classification & Feed $(<53 \mu)$ & EF-138 & 0.95 & 9.01 & 90.99 & 1.81 & 6.75 & 5.7 & 3.7 \\
\hline \multirow[t]{3}{*}{ None } & First float & EF-366 & 1.10 & 14.31 & 85.69 & 16.23 & 22.01 & 38.1 & 5.2 \\
\hline & Second float & EF-367 & 1.12 & 5.14 & 94.86 & 5.99 & 16.23 & 6.2 & 4.1 \\
\hline & Tailing & EF-370 & 6.16 & 6.60 & 93.40 & 65.78 & 36.38 & 20.9 & 5.1 \\
\hline \multirow[t]{2}{*}{ Ferric } & First float & EF-371 & 1.16 & 12.75 & 87.25 & 20.14 & 26.46 & 46.3 & 12.2 \\
\hline & Tailing & EF-375 & 3.79 & 25.55 & 74.45 & 49.06 & 32.06 & 12.2 & 5.2 \\
\hline \multirow[t]{3}{*}{ Nitric } & First float & $\mathrm{EF}-376$ & 1.09 & 15.63 & 84.37 & 15.98 & 20.24 & 34.9 & 10.9 \\
\hline & Second float & EF-377 & 1.51 & 4.97 & 95.03 & 5.41 & 13.99 & 6.7 & 4.3 \\
\hline & Tailing & $E F-380$ & 9.19 & 35.49 & 64.51 & 59.01 & 29.93 & 8.7 & 3.8 \\
\hline
\end{tabular}

higher in the tailings, showing that mixed grains with a high ratio would approach the behaviour of pure pyrite.

Nevertheless, the relative amount of liberated pyrite in the first floats is unexpectedly high ( $\geq 12.75 \%$ ), being highest in the samples with nitric pre-treatment $(15.63 \%)$, although these still show the best behaviour, as far as pyrite depression is concerned ( 9.19 vol\% in the tailings). Figs. 7 and 8 show the distribution of pyrite (Py) in first float concentrates for each treatment as respects: modal pyrite content in mixed particles (free pyrite being represented by the class $100 \%$ pyrite) in Fig. 7; pyrite grain size, in Fig. 8. The same is shown in Figs. 9 and 10, for second float concentrates.

The different behaviour of pyrite in the first and second floats can be easily seen, comparing Figs. 7 and 9 . The tendency of liberated pyrite to be concentrated in the first float is apparent, but the most striking difference is shown by the distribution of pyrite among the various compositional classes. Middlings are mostly pyrite-rich in

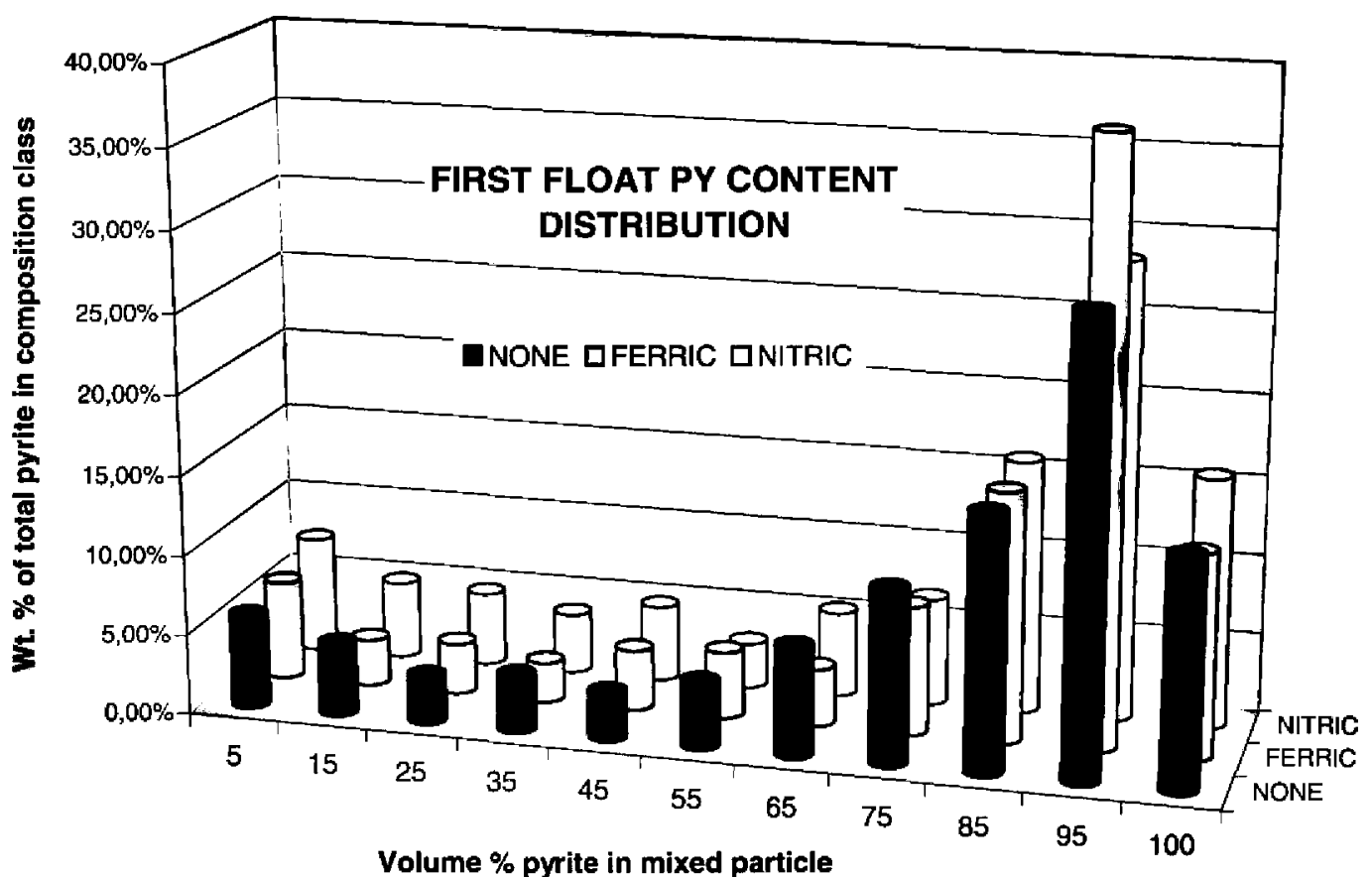

Fig. 7. First float Py content distribution. 


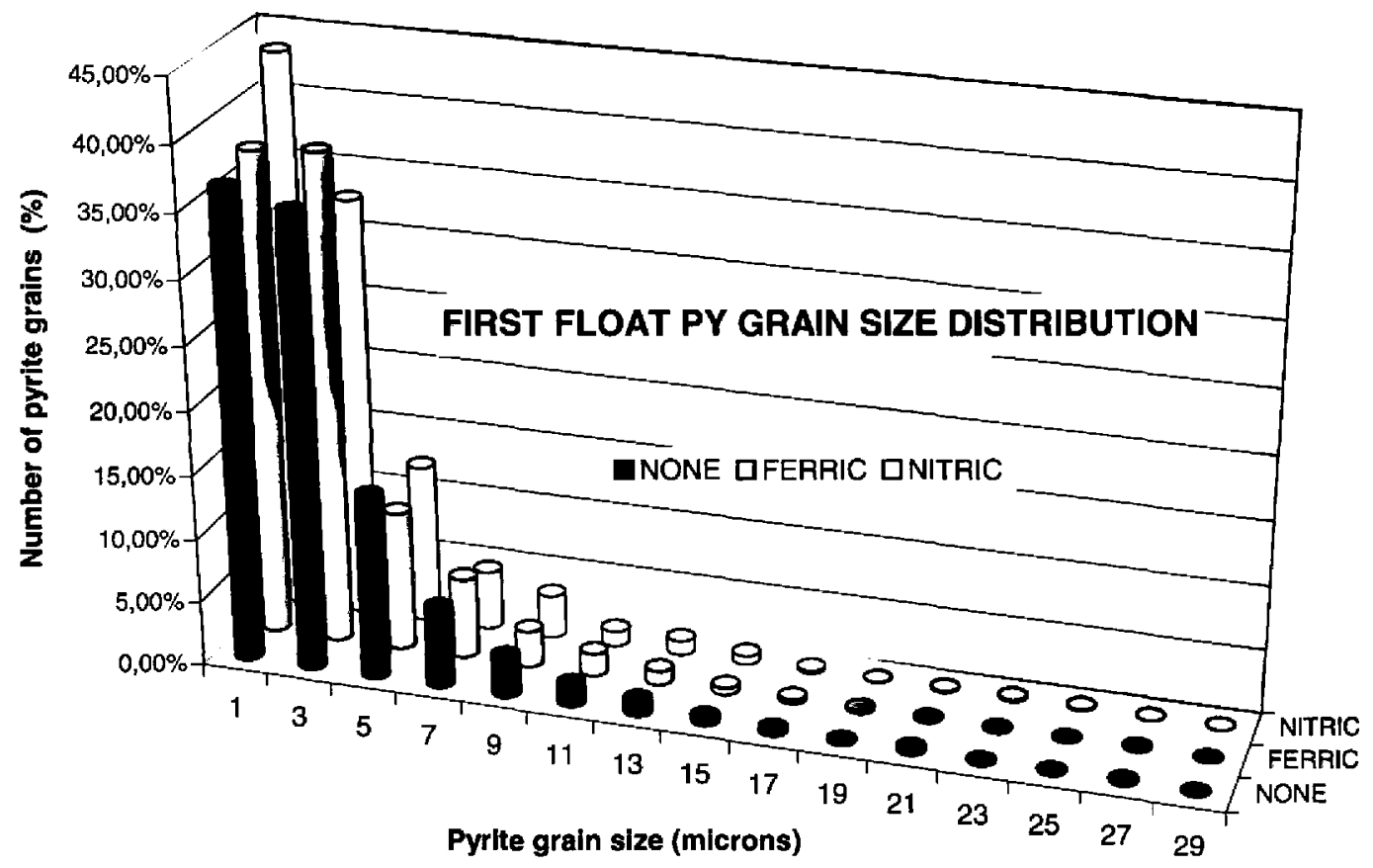

Fig. 8. First float Py grain size distribution.

first floats (e.g. about $30-35 \%$ of total pyrite is contained in mixed grains with $95 \%$ modal pyrite), contrasting with pyrite-poor compositions in second floats (around 30-35\% of total pyrite in grains with $5 \%$ modal pyrite). This is not explained by the higher exposition ratio of pyrite in the first case (Table 5). As for the grain size distribution, in both cases (especially in the second floats) most of the pyrite grains are fine to very fine, with over $80 \%$ of the grains less than $5 \mu \mathrm{m}$.

As far as the tailings are concerned (Table 5), their content of pyrite (as compared with floats, feed and ROM coal) should be higher, corresponding to the efficiency of the pyrite depression process, and it is actually higher in all the cases. The same can be said of the exposition ratio,

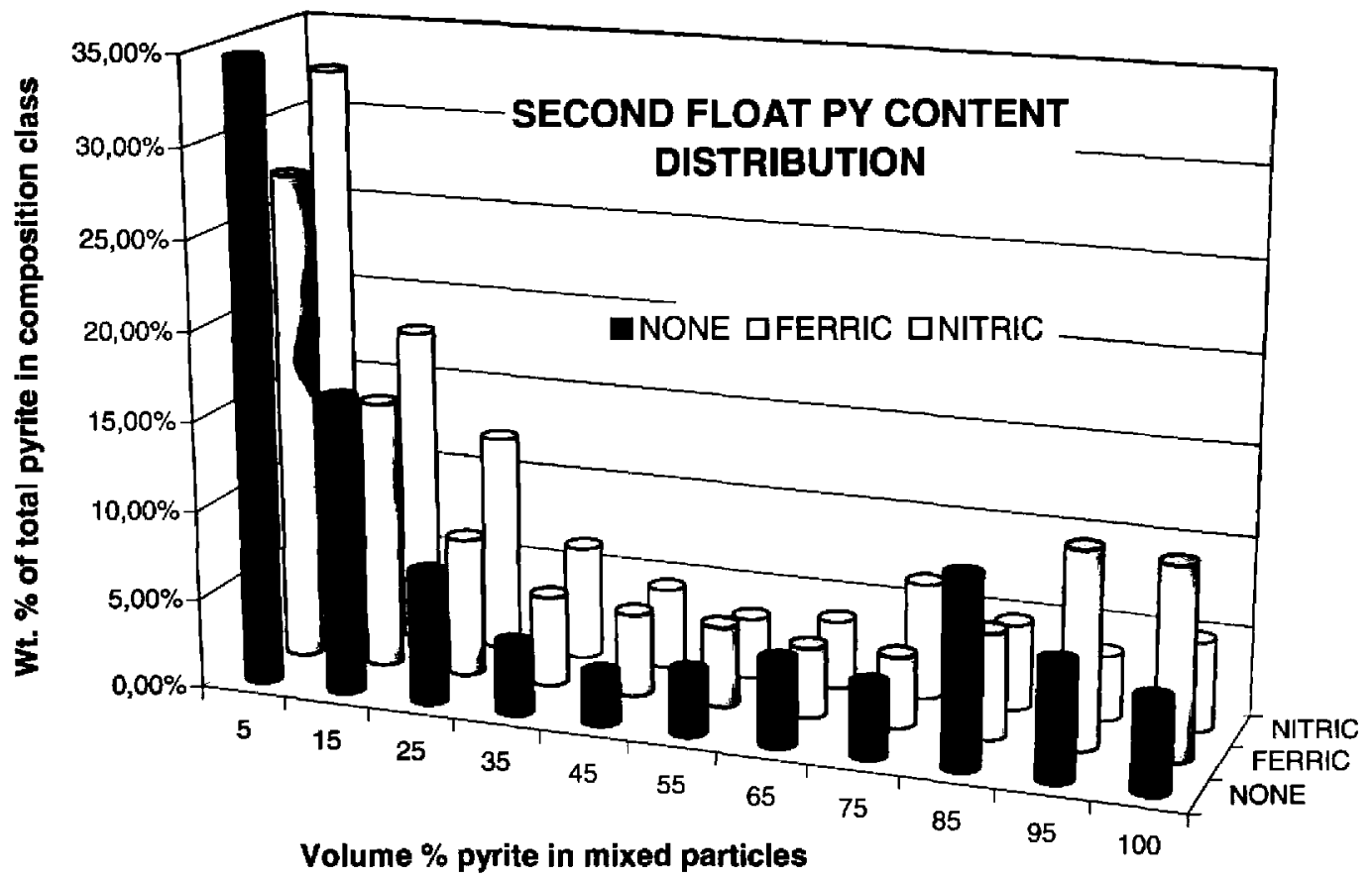

Fig. 9. Second float Py content distribution. 


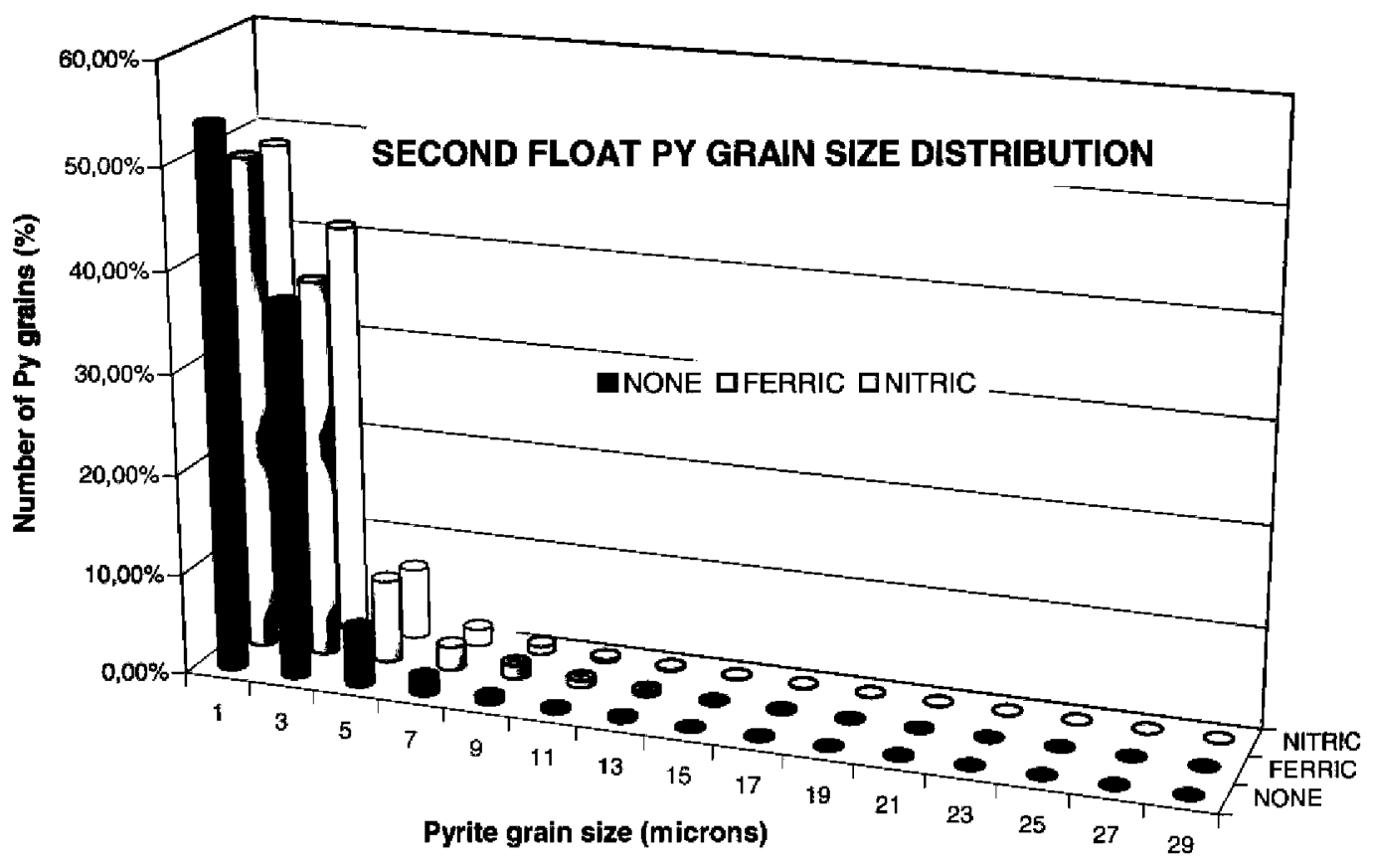

Fig. 10. Second float Py grain size distribution.

which in the tailings reaches its highest values in all the cases, showing that the pyrite effectively depressed was less coated by coal and therefore more able to react as mineral pyrite and/or more exposed to the reagents that contribute to the process. Moreover, the distribution of pyrite in the tailings, as compared with the floats, should favour free pyrite with respect to mixed grains, and this is what happens in both cases of pre-treated coal.

The clue to the behaviour of pyrite lies therefore in the combination of pyrite grain size, pyrite grade in coal and type of pyrite intergrowth with coal. This is conveniently expressed by means of the exposition ratio, as shown. Still, the unexpected relative enrichment of 'free' pyrite in the first floats needs a further explanation, the more so as the grain size of this free pyrite tends to be coarser than the one in second floats or in the tailings (Table 5). The information obtained by qualitative microscopic examination of the products explains this behaviour: the dominant form of pyrite in the first floats is the so called framboidal pyrite (Fig. 1), i.e. fine-grained aggregates of very minute crystals or colloidal particles (most often $<$ micron-sized) of the mineral, intergrown with tiny specks of coal or organic matter, showing a more or less rounded external shape and a compact appearance. The internal structure of each individual framboid lies usually below the resolution power of the system - for the magnification used-, so that these aggregates are measured as single pyrite grains, while in fact they are a porous mixture of tiny particles that may behave as a mixed pyrite + coal grain. The resulting behaviour may be flotation or depression, depending on the particular composition, recrystallization history, and exposition ratio in each case. These results are in agreement with the findings of Wang et al. [10], except that in this case not only the 'particles containing a high amount of carbonaceous material' but also a certain amount of pyrite-rich particles are concentrated in the first float: the pyrite framboids just mentioned.

\section{Conclusions}

The oxidative pre-treatment of pyrite-bearing coal samples to improve the separation of the sulphide was tested with nitric and with ferric reagents, and the results were compared with those obtained with non pre-treated samples of the same coal. Pyrite hydrophobicity survives the oxidative pre-treatment in some cases, in which no real pyrite depression occurs.

To understand the behaviour of pyrite, all the stages of the processes involved were followed-up closely, through a detailed mineralogical study coupled to DIA of all the samples, which provided essential clues to explain the unexpected results of the flotation process:

- Pyrite is present as small and compact crystals or veinlets (mineral pyrite) or as small particles intergrown with coal and framboidal pyrite (coal pyrite), both types showing a different behaviour.

- Framboidal pyrite of very fine-grained internal structure (down to sub-micron sized particles intergrown with coal) can survive oxidative pre-treatment and, due to its hydrophobicity, concentrate with first float products. This pyrite has the appearance of 'liberated pyrite', although its hydrophobic behaviour is dictated by its porosity and by its coal content. It explains 
the anomalous contents of 'free pyrite' of pre-treated first floats.

- Mineral pyrite, when liberated, behaves as expected and concentrates in the tailings.

- The behaviour of mineral pyrite in mixed grains can be explained by the exposition ratio, a morphologic parameter which can be quantified with DIA and which informs about the relative amount of pyrite exposed to the reagents. Middlings with high ratios approach the behaviour of mineral pyrite and tend to be concentrated in tailings, while those with lower values show a higher hydrophobicity.

- The second float products are enriched in locked or coated (unliberated) pyrite, as shown by their lower (exposition ratio, Table 5).

- Depression of liberated pyrite into tailings is increased by $300 \%$ with ferric, and by $>400 \%$ with nitric oxidative pre-treatments, as compared with not pre-treated samples $(25.55,35.49$, and $6.6 \%$, respectively, Table 5).

Finally, the image analysis has shown that the oxidative pre-treatments were effective on liberated nonporous pyrite, depressing it. Nevertheless, these surface pre-treatments seem not to affect the floatability of porous, framboidal pyrite, due possibly to its intrinsic hydrophobicity. Thus, mineralogical studies coupled to DIA may provide an efficient, relatively simple and unexpensive tool to gain an insight into the problems raised by coal processing, particularly those related to the occurrence of sulphides in coal and their necessary elimination.

\section{Acknowledgements}

The support of Profs R. Ezama and F. Elorza (ETSI Minas,UPM) and their helpful discussions on the topic are gratefully acknowledged. The research was supported by funding from FIENER (ETSI Minas Madrid/F. Gomez Pardo) through a personal fellowship of the first author, and from projects GR92-0135, UE95-0007 and UE98-0027 (Ministerio de Educación y Cultura, MEC, Spain) for the instrumentation used. We would also like to thank the laboratories of IGME and INCAR for the preparation of the polished sections. The very helpful comments of the editor, Prof. J.W.Patrick, and two anonymous reviewers are also thankfully acknowledged.

\section{References}

[1] Choundhry V, Aplan FF. Miner Metall Process 1992;51-6.

[2] Kawatra SK, Eisele TC. Int J Miner Process 1997;50:187-201.

[3] Alvarez R, Clemente C, Gómez-Limón D. Fuel 1996;75(5):606-12.

[4] Ramdohr P. The ore minerals and their intergrowths. Heidelberg: Pergamon Press; 1969

[5] Pirard E. Eur Microsc Anal 1999;60:9-11.

[6] Criddle A, Stanley C. Quantitative data file for ore minerals, 3rd ed. London: Chapman \& Hall; 1993.

[7] Castroviejo R, López A, Múzquiz C, Pirard E. In: Pirard E, editor. Proceedings of Geovision'99. Univ. Liège; 1999. p. 41-4.

[8] Castroviejo R, Chacón E, Múzquiz C, Tarquini S. In: Pirard E, editor. Proceedings of Geovision'99. Univ. Liège; 1999. p. 41-4.

[9] Petela R, Petela G. Fuel 1996;75(11):1259-66

[10] Wang D, Adel GT, Yoon RH. Miner Metall Process 1993;154-9. 